\title{
Correction: Liss, K.-D., et al. Hydrostatic Compression Behavior and High-Pressure Stabilized $\beta$-Phase in $\gamma$-Based Titanium Aluminide Intermetallics. Metals 2016, 6, 165
}

\author{
Klaus-Dieter Liss ${ }^{1,2,3, *}$ (D) , Ken-Ichi Funakoshi ${ }^{4}$, Rian Johannes Dippenaar ${ }^{3}$, Yuji Higo ${ }^{5}$, \\ Ayumi Shiro ${ }^{6, \dagger}$, Mark Reid ${ }^{2,3}$, Hiroshi Suzuki ${ }^{1, \ddagger}$, Takahisa Shobu ${ }^{6, \ddagger}$ and Koichi Akita ${ }^{1, \ddagger}$ \\ 1 Quantum Beam Science Center, Japan Atomic Energy Agency, Tokai, Ibaraki 319-1195, Japan; \\ suzuki.hiroshi07@jaea.go.jp (H.S.); akita.koichi@jaea.go.jp (K.A.) \\ 2 Australian Nuclear Science and Technology Organisation, Lucas Heights 2234, Australia; \\ mark.reid@ansto.gov.au \\ 3 School of Mechanical, Materials \& Mechatronic Engineering, Faculty of Engineering and Information \\ Sciences, University of Wollongong, Northfields Avenue, Wollongong 2522, Australia; rian@uow.edu.au \\ 4 Neutron Science and Technology Center, Comprehensive Research Organization for Science and \\ Society (CROSS-Tokai), Tokai, Ibaraki 319-1106, Japan; k_funakoshi@cross.or.jp \\ 5 SPring-8, Japan Synchrotron Radiation Research Institute, Kouto, Sayo, Hyogo 679-5198, Japan; \\ higo@spring8.or.jp \\ 6 Quantum Beam Science Center, Japan Atomic Energy Agency, Kouto, Sayo, Hyogo 679-5148, Japan; \\ shiro.ayumi@qst.go.jp (A.S.); shobu@sp8sun.spring8.or.jp (T.S.) \\ * Correspondence: kdl@ansto.gov.au or liss@kdliss.de; Tel.: +61-2-9717-9479 \\ † Present Address: Quantum Beam Science Research Directorate, National Institute for Quantum and \\ Radiological Science and Technology, Kouto, Sayo, Hyogo 679-5148, Japan. \\ $\ddagger \quad$ Present Address: Materials Sciences Research Center, Japan Atomic Energy Agency, Tokai, Ibaraki 319-1195, \\ Japan and Kouto, Sayo, Hyogo 679-5148, Japan.
}

Received: 15 August 2017; Accepted: 22 August 2017; Published: 7 September 2017

The authors would like to apologize for any inconvenience regarding misleading errors and inconsistencies in some of the units and one number, and wish to make the following corrections to this paper [1]:

Page 11: unit should be GPa in "... up to $200 \mathrm{GPa}$ [71] ... " (not MPa).

Page 12: unit should be GPa in " ... lying around $146 \mathrm{GPa} . .$. " (not MPa).

Figure 9: units should be GPa for $K_{0}$ in all four occurrences (not MPa).

Table 1: add to caption: " $a, c$ in $(\AA) ; V$ in $\left(\AA^{3}\right) ; K_{0}$ in (GPa)."

Table 1: correct value for $K_{0}$ for $\alpha_{2}$ to be "126" (not 116).

Page 16: unit should be GPa in "With values around $146 \mathrm{GPa} . .$. " (not MPa). 


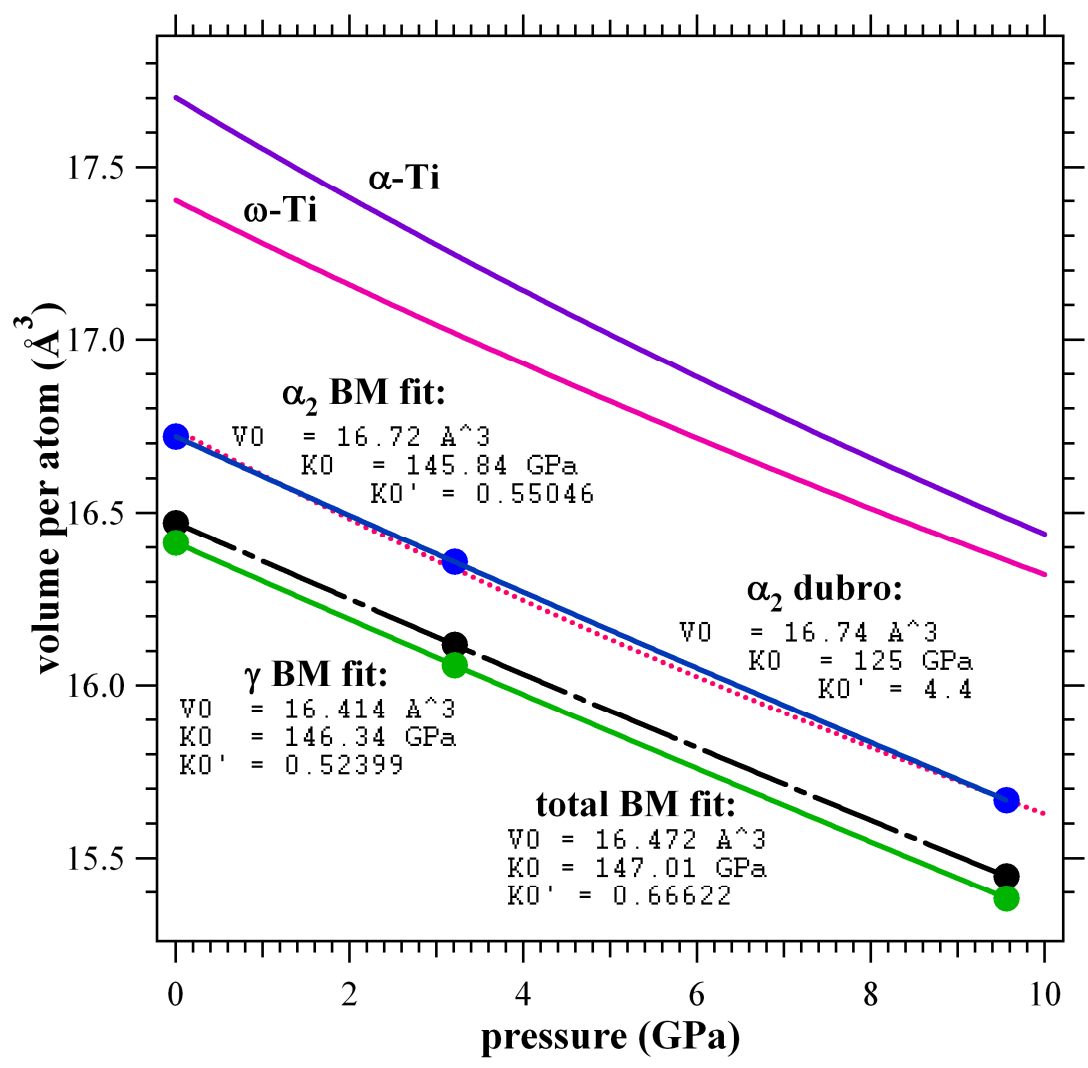

Figure 9. Atomic volumetric compression behavior of the investigated composition Ti-45Al-7.5Nb-0.25C with Birch-Murnaghan fits (experimental dots with continuous lines), as compared to $\alpha_{2}$-single-phase compression, and $\alpha$ - and $\omega$-titanium, reported by Dubrovinskaia [59] and Errandonea [48], respectively.

Table 1. Compilation of experimental lattice parameters $a_{0}$ and $c_{0}$ under ambient conditions, as well as the derived quantities; their axis ratios and volume per atom $V_{\mathrm{A}}$, compression parameters $K_{0}, K_{0}{ }^{\prime}$ (first three rows) and data from the literature. The $\alpha$-phase lattice is given in $\alpha_{2}$ cell notation, and therefore, $2 c / a$ is noted. The first $V$ A column is computed from $a_{0}$ and $c_{0}$, while the second results are from the fit of pressure data to Equation (6). The original data of Yeoh's publication [31] has been re-visited to extract the listed values at $300 \mathrm{~K}$. Literature values are reported from their experimental findings, in addition to Ghosh's first-principles study [61]. Further listed references are Dubrovinskaia [59],

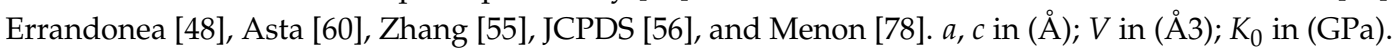

\begin{tabular}{|c|c|c|c|c|c|c|c|c|}
\hline Phase & $a_{0}$ & $c_{0}$ & Axis Ratio & $V_{\mathrm{A}}$ & $V_{\mathrm{A}}$ & $K_{0}$ & $K_{0}^{\prime}$ & Reference \\
\hline$\gamma$ & 4.01867 & 4.06542 & 1.0116332 & 16.4138371 & 16.414 & 146.34 & 0.52399 & this work \\
\hline$\alpha / \alpha_{2}$ & 5.76803 & 4.64241 & 1.60970383 & 16.7201111 & 16.72 & 145.84 & 0.55046 & this work \\
\hline total & & & & 16.4720291 & 16.472 & 147.01 & 0.66622 & this work \\
\hline$\alpha_{2}-\mathrm{Ti}-33.3 \mathrm{Al}$ & 5.7763 & 4.6348 & 1.6047643 & 16.7406041 & 16.74 & 125 & 4.4 & Dubrovinskaia \\
\hline$\alpha_{2}-\mathrm{Ti}-28.4 \mathrm{Al}$ & 5.7829 & 4.6388 & 1.60431617 & 16.7933623 & 16.79375 & 131 & 3.6 & Dubrovinskaia \\
\hline$\alpha_{2}-\mathrm{Ti}-24.0 \mathrm{Al}$ & 5.8083 & 4.6563 & 1.60332627 & 17.0051191 & 17.005 & 133 & 2.6 & Dubrovinskaia \\
\hline$\alpha-\mathrm{Ti}$ & & & 1.583 & & 17.7013462 & 117 & 3.9 & Errandonea \\
\hline$\omega$-Ti & & & 0.609 & & 17.4024491 & 138 & 3.8 & Errandonea \\
\hline$\gamma$ & & & 1.012 & & & 128 & & Asta \\
\hline$\alpha_{2}$ & & & 1.698 & & & 126 & & Asta \\
\hline$\gamma$ & 3.9814 & 4.0803 & 1.02484051 & 16.1697657 & 16.181 & 112.1 & 3.91 & Ghosh \\
\hline$\alpha_{2}$ & 5.7372 & 4.6825 & 1.63232936 & 16.6847003 & 16.584 & 111.9 & 3.83 & Ghosh \\
\hline$\alpha-\mathrm{Ti}$ & & & 1.5868 & & & 114 & 4 & Zhang \\
\hline$\alpha-\mathrm{Ti}$ & 5.901 & 4.6826 & 1.58705304 & 17.651391 & & & & JCPDS \\
\hline$\gamma$-Ti-50Al & 3.9973 & 4.0809 & 1.02091412 & 16.3015706 & & & & Menon \\
\hline$\gamma-\mathrm{Ti}-45 \mathrm{Al}-7.5 \mathrm{Nb}-0.5 \mathrm{C}$ & 4.02421 & 4.07335 & 1.01221109 & 16.4912285 & & & & Yeoh \\
\hline$\alpha_{2}-\mathrm{Ti}-45 \mathrm{Al}-7.5 \mathrm{Nb}-0.5 \mathrm{C}$ & 5.77568 & 4.65646 & 1.61243698 & 16.8152283 & & & & Yeoh \\
\hline
\end{tabular}




\section{Reference}

1. $\quad$ Liss, K.-D.; Funakoshi, K.-I.; Dippenaar, R.J.; Higo, Y.; Shiro, A.; Reid, M.; Suzuki, H.; Shobu, T.; Akita, K. Hydrostatic Compression Behavior and High-Pressure Stabilized $\beta$-Phase in $\gamma$-Based Titanium Aluminide Intermetallics. Metals 2016, 6, 165. [CrossRef] 